\title{
Does Belief Aim (Only) at the Truth?
}

\section{Daniel Whiting}

The definitive version of this article is to be published in Pacific Philosophical Quarterly (2012) by Wiley-Blackwell, and will be available at http://onlinelibrary.wiley.com/. Please refer to the published version.

\begin{abstract}
It is common to hear talk of the aim of belief and to find philosophers appealing to that aim for numerous explanatory purposes. What belief's aim explains depends, of course, on what that aim is. Many hold that it is somehow related to truth, but there are various ways in which one might specify belief's aim using the notion of truth. In this paper, by considering whether they can account for belief's standard of correctness and the epistemic norms governing belief, I argue against certain prominent specifications of belief's aim given in terms of truth and advance a neglected alternative.
\end{abstract}

It should not be imagined that there is much to endure in the search after truth.

(Malebranche)

Error is the cause of men's misery [...] We may hope for sound and genuine happiness only by seriously labouring to avoid it.

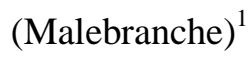




\section{$1 \quad$ Liberals and conservatives}

It is common to hear talk of the aim of belief and to come across philosophers invoking such an aim for various explanatory purposes. For example, philosophers appeal to belief's aim in attempting to account for what distinguishes belief from other psychological attitudes (Railton 1994; Velleman 2000), the normativity of mental content (Boghossian 2008, ch. 4), the nature and force of theoretical reasoning (Velleman 2000), the character of deliberation concerning what to believe (SteglichPetersen 2006), the paradoxical nature of Moorean beliefs such as that it's raining but I don't believe that it's raining (Millar 2009; Railton 1994; Williams 1973, p. 137), belief’s standard of correctness (see $\S 4$ below), the epistemic norms governing belief (see $§ 5$ below), that subjects are motivated (not) to believe certain things on the basis of the evidence they take themselves to possess (McHugh Forthcoming; SteglichPetersen 2009, pp. 395-396) and that subjects cannot believe at will (Engel 2002, pp. 133-134; Williams 1973, ch. 9).

It would be nice if belief's aim could explain such things. But that depends on what that aim is. Arguably, philosophers most frequently appeal to the notion of truth when specifying it. However, there are various ways in which one might formulate the aim of belief in this way, including:

(LIB) Belief aims at the truth.

(CON) Belief aims only at the truth.

In the next section, I shall spell out how I understand the aims here attributed. For now, note that (LIB) is the orthodox construal of belief's aim; it is by far the most common way in which philosophers characterise that aim using the notion of truth. ${ }^{2}$ In contrast, $(\mathrm{CON})$ is somewhat neglected. ${ }^{3}$

The distinction between (LIB) and (CON) is rarely noted; where it is, it is not usually accorded much importance. There is a tendency for philosophers to move 
without comment from one formulation of belief's aim to the other or to a combination of both, assuming, perhaps, that the difference between them is merely notional. ${ }^{4}$ The difference is, however, substantive. One place in which this shows up, as I shall discuss below, is in philosophers' attempts to put (LIB) to explanatory uses which are in fact not served by it but by (CON), and vice versa.

One aim of this paper is to show that the superficial similarity between (LIB) and (CON) hides great differences. First, I shall argue that, at the intuitive level, it is more plausible to think that (CON), rather than (LIB), captures belief's aim. Others have noted that (LIB) is somewhat counterintuitive but here I address some responses to this charge which have yet to receive attention. Moreover, it is often thought that (CON) is equally counterintuitive, a charge I shall reject. Next, I shall argue for (CON) and against (LIB) by examining certain of the explanatory purposes to which philosophers have put the idea that belief has an aim. In particular, it is widely held that, if (LIB) were true, it would explain belief's standard of correctness. However, I shall argue that (LIB) fails in this respect and that it is instead (CON) which accounts for belief's correctness-condition. Second, I shall show that (LIB) and (CON) present very different accounts of the normative considerations pertaining to belief and evidence. While the picture (LIB) presents might initially seem more promising, I shall argue that it is mistaken. In closing, I shall turn to a rather different conception of belief's aiming at truth, which Velleman, among others, advances and which might seem to avoid the difficulties (LIB) faces, and suggest that it is explanatorily inadequate.

The result of what follows will, I hope, be to show how important it is for philosophers to keep (LIB) and (CON) firmly apart and to make a case for thinking that, when kept apart in this way, (CON) is a more promising and explanatorily abundant way to formulate belief's aim than (LIB). ${ }^{5}$ 


\section{$2 \quad$ Setting the stage}

Before proceeding to explore the differences between (LIB) and (CON), several preliminary remarks are in order.

First, I shall restrict my attention to the idea that the psychological attitude or mental state of believing has an aim, or that subjects have certain aims with regard to that attitude or mental state. A related thought is that the activity of inquiry —of investigating some subject matter with a view to finding something out about it - and the practices it involves have an aim or goal, which one might also specify using the notion of truth (see Kvanvig 2003, pp. 8-9; Lynch 2005, pp. 13-15; Lynch 2009, pp. 226-227). Though one might expect there to be important connections between the aims of belief and of inquiry—not least because the upshot of inquiry is, or is supposed to be, belief concerning the relevant subject-matter-I shall set aside for present purposes the issue of what the goal of inquiry is, assuming there is one. ${ }^{6}$

Second, I shall focus only weighing up competing formulations of belief's aim given in terms of truth. The most prominent alternative is to construe belief's aim in terms of knowledge. ${ }^{7}$ I shall not examine the pros and cons of this approach, since there is enough here to be getting on with. That said, it is consistent with the formulation of belief's aim which I shall recommend, namely (CON), that that aim is ultimately to be cashed out in terms of knowledge. Perhaps belief aims only at truth in aiming only at knowledge.

Third, one might object that we are not forced to choose between (LIB) and (CON). Perhaps belief aims at the truth and only at the truth. ${ }^{8}$ However, some of the objections I shall level at (LIB) apply equally to the conjunction of (LIB) and (CON). So, there is no harm in focusing on the conjuncts individually and it makes for a more straightforward presentation to do so. 
Fourth, I am not going to argue at length for the very idea that belief has an aim or provide direct responses to objections to that idea (e.g. Owens 2003). The focus, rather, is on adjudicating a dispute among those who hold that belief has an aim concerning how that aim should be construed. On the face of it, this issue is prior; one cannot settle whether or not belief has an aim in the absence of some concrete proposal as to what that aim might be. That said, I shall provide indirect support for the idea that belief has an aim — and, more specifically, that that aim can be profitably cashed out in terms of truth—by distinguishing (CON) from (LIB), and thereby distancing the strengths of (CON) from the weaknesses of (LIB).

Fifth, it is often alleged that belief cannot literally have an aim (e.g. Lynch 2004, p. 499; Wedgwood 2002, p. 267). Beliefs are states or attitudes of subjects and, unlike subjects, not the sorts of things that can aim at anything. In attempting to unpack talk of belief's aim, some take it as shorthand for talk of the causal regulation of belief states for truth at a sub-personal level (e.g. Velleman 2000). For reasons examining which would take us too far afield, ${ }^{9}$ I prefer to view the aim as one subjects possess at a personal level (which is not to reject claims about goings-on at the sub-personal level). ${ }^{10}$

In general, a person's aim is her goal; it is a thing wanted. ${ }^{11}$ So understood, an aim is that for the sake of which one acts and towards which one's actions are directed. When one takes oneself to have undefeated reasons for having a certain aim, one might adopt it as one's goal, in which case one's goal is one's intended end or one's intention. For example, I might take the fact that I need to lose weight and the fact that I could raise sponsorship for a worthy cause to provide conclusive reasons for running a marathon. As a result, I might adopt running a marathon as a goal and, in doing so, form the intention to run a marathon, for the sake of which I start training. I shall conceive of the aim of belief as an agent's goal in this sense, though I shall not 
take a stand on whether the aim is also a believer's intention. ${ }^{12}$ If one is unsympathetic to the conception of an aim I am exploiting, little in what follows hangs on it and the discussion could be reformulated in the preferred terms.

Sixth, several philosophers claim that (in some sense) it is constitutive of an attitude's being belief that it is formed with or governed by the relevant aim. This issue is contentious and not my immediate concern. For present purposes, I shall assume that it is at least necessary for having beliefs that one has the relevant aimthat the aim is not a contingent goal believers just happen to have-though nothing in what follows turns on this.

Finally, in light of the above, I shall make explicit how I understand the aims (LIB) and (CON) attribute. According to (LIB), as I shall construe it, subjects aim to believe the truth, which is to say that subjects aim to believe a proposition if it is true. This corresponds to how many philosophers understand belief's aim ${ }^{13}$ and, more importantly, it is a natural way to interpret talk of the aim to believe the truth. If I aim to steal the treasure, I will surely not be satisfied unless I steal all of it. Aiming to eat the cake is not the same as aiming to eat cake, or aiming to eat a portion of the cake. Consider also the following, seemingly innocent chain of reasoning: My aim is to meet the cast of Star Wars, but I've yet to meet Anthony Daniels, so I shall track him down. Naturalness aside, should my construal of (LIB) not suggest itself to others or fail to capture the thesis certain philosophers mean to advance, I shall consider other (more modest) aims as I proceed and it remains an independently interesting question whether (LIB), so construed, is true.

According to (CON), as I shall construe it, subjects aim to believe only the truth, which is to say that subjects aim to believe a proposition only if it is true, which in turn is to say that subjects aim not to believe a proposition if it is false. ${ }^{14}$ Again, this reading is natural. If I aim to watch only English-language films, I might ensure I 
achieve this by watching no films whatsoever. Aiming to purchase only Picassos is not the same as aiming to purchase all Picassos, all and only Picassos, or, indeed, any Picassos. ${ }^{15}$ Consider also the following, seemingly innocent chain of reasoning: My aim is to drink only the organic juice, and all that's left is non-organic juice, so I shall not drink any juice. Naturalness aside, I shall suggest that, so interpreted, (CON) is defensible.

\section{Divine aspirations}

One obvious problem facing (LIB) is that the aim it attributes to subjects is unsatisfiable; finite believers cannot possibly achieve it. The relevant aim would be satisfied only if a subject believed all truths, yet there are infinitely more truths than any finite subject can believe and infinitely many truths too complex for any such subject to believe. It seems strange, if not incoherent, to attribute to believers such a manifestly unattainable aim.

An ardent proponent of (LIB) might not be moved by these considerations. The aim (LIB) attributes, she might suggest, is an ideal; though it is not achievable, it is something believers can aspire to. It is no sillier, she might continue, to attribute this aim to believers than it is to attribute to humans the desire to lead good lives.

One might worry that this reply does not take full measure of the concern, since the relevant goal is not one finite believers can even come close to; we are able to believe only a minute fraction of the infinite truths that there are. Quite apart from issues of achievability, the aim simply looks, to put it bluntly, a bit daft. Many, indeed most, truths are utterly trivial. ${ }^{16}$ Consider, for example, all the truths about the length and colour of each hair on David Cameron's left arm. Why would anyone have as her goal believing such things? Whether all truths are believable or not, the vast majority 
are not worth believing. Since one would expect any reasonable person to see this, one should not expect such persons to have as their aim believing all truths.

In response, (LIB)'s advocate might complain that these concerns trade on illegitimate considerations. Of course, she might protest, it does not appear to be worth believing the allegedly trivial truths about Cameron's arm-hairs from the practical point of view — doing so would not further any of one's practical goals — but this is precisely because action is not governed by the same aims as belief. However, she continues, the claim is only that it is worth believing such things from the epistemic point of view, that qua believer one aims to believe the truth (though qua agent one does not). So, the reply concludes, the aim (LIB) attributes only seems daft when viewed from a foreign perspective which does not share this aim, not when one inhabits the native perspective of the believer herself.

This reply does not get us far. It will not do simply to appeal to the epistemic perspective since the present dispute precisely concerns how to construe that perspective, that is, how best to specify the aim which characterises and informs it. Perhaps (LIB)'s proponent can reformulate the thought behind the reply without relying on the notion of an epistemic perspective. ${ }^{17}$ The point, she might say, is that, while we aim to believe the truth, we are complex creatures with various goals, many of them practical. We need to act as well as think! Often, these practical goals compete with the aim to believe the truth and, when the practical goals take precedence, we are not inclined to believe truths if doing so is not in the service of or conflicts with those goals, in which case, we do not view believing such truths to be worthwhile. It would be a mistake, the reply concludes, to take the fact that the aim, as captured by (LIB), is often, or even typically, overridden to show that believers have no such aim at all. 
The worry remains, however, that this line of thought does not speak to the original objection. Suppose that one's practical goals allow for one to believe the truth about the number of hairs on David Cameron's arms. It remains extremely difficult to see why one would want to, or to imagine a person having this as her aim.

To make the same point a different way, reintroducing talk of perspectives, it just does not seem to be the case that believing trivial truths appears pointless only from the practical perspective. Grimm, though his main focus is not the idea that belief has an aim, explicitly takes himself to be adopting the epistemic perspective when he makes the point: 'If you propose an evening memorizing the phone book for Topeka, Kansas, and I decline, have I really missed an opportunity to enrich myself, from an epistemic point of view?' (2008, p. 726; see also David 2005, pp. 298-299; Feldman 2000, p. 683). So, it does not appear to be the presence of competing practical aims and considerations which make the aim to believe a proposition if it is true seem an aim not worth having. ${ }^{18}$

One might try to evade the above difficulties by revising (LIB) so that it attributes a more discriminating aim:

(NEOLIB) Belief aims at those truths one considers. ${ }^{19}$ According to (NEOLIB), as I shall construe it, a subject aims to believe a proposition she considers if it is true. Alternatively, if a subject considers a proposition, she aims to believe it if it is true. While this might make the aim achievable-assuming that one can believe anything one can consider-it remains possible, perhaps likely, that among the truths one considers are utterly trivial truths, in which case it is hard to understand why one would aim to believe them. Limiting the scope of belief's aim, as (NEOLIB) does, only postpones this problem rather than resolves it.

Furthermore, supposing that one aims to believe those truths one considers, it is not clear that this reflects an aim one has in believing as opposed to an aim one has 
in considering. Consideration is a purposive activity and, arguably, one goes in for it with the goal of believing the truth. A case can be made, then, that (NEOLIB) is a somewhat infelicitous statement of the aim of considering, in which case, it is of no use to those attempting to specify the aim of believing.

Evidently, I have not shown (LIB), or the restricted version of it, to be false but I hope to have shown it to be a rather counterintuitive way of characterising belief's aim. Of course, there might be strategies available to (LIB)'s proponent to respond to this challenge. However, I shall not rest my case on the above considerations. In the next sections, I shall turn to evaluate the explanatory potential of (LIB) and (NEOLIB) and argue that they do not hold much promise in this regard.

(CON), one might complain, is no more promising than (LIB). The problem is not so much that the aim (CON) attributes to believers is one of being infallible - an ideal we might approximate to, even if we inevitably fall short of it - but rather that the aim it attributes could be achieved if one had no beliefs at all. ${ }^{20}$ Surely, one's aim qua believer cannot be to believe nothing.

I do not think that this highlight a problem akin to that facing (LIB). In the first instance, (CON) is compatible with the fact that subjects have additional aims, theoretical or practical, for the sake of which those subjects need to have various beliefs. All that (CON) maintains is that, in having those beliefs, subjects aim not to believe falsely. More importantly, while the aim (LIB) attributes is achieved in only one circumstance, namely, when a subject believes all truths, the aim (CON) attributes is not achieved only when a subject believes nothing; it would be achieved when a subject believes any number of things, none of which are false. So, it is not the aim to believe nothing and it is satisfiable, at least in principle. Also, the aim is not daft; it is not obviously silly to aim to avoid believing if in doing so one will believe falsely, however trivial the belief. While it seems daft to want to believe that David Cameron 
has $n$ hairs on his arms, if he does, it does not seem daft to want not to believe this, if he does not. ${ }^{21}$

Again, I shall not rest my case for (CON) on these considerations. Instead, I shall highlight its explanatory potential, which is the focus for the remaining sections.

\section{$4 \quad$ Setting the standard}

The following is, surely, the merest platitude:

(CORRECT) For any $p$, believing that $p$ is correct if and only if it is true that $p$

To my knowledge, all parties to the debate accept (CORRECT), whether they advocate (CON) or (LIB) or reject the very idea of an aim of belief. ${ }^{22}$

As mentioned above, it is common for philosophers to appeal to belief's aim in trying to account for the fact that belief's correctness-condition is truth. And it is most common to invoke (LIB) in explaining the standard to which belief is subject. As Velleman states this ambition, 'To say that belief aims at the truth is not simply to reexpress the norm stipulating that a belief must be true in order to be correct; rather, it is to point out a fact about belief that generates this norm for its correctness' (2000, pp. 16-17; cf. Humberstone 1992; Papineau 1999; Steglich-Petersen 2009). ${ }^{23}$

At a first stab, the explanation proceeds as follows. Subjects aim to believe the truth. This aim sets a standard for a given subject's believing according to whether or not she achieves her aim in doing so. A subject's beliefs are correct or incorrect insofar as they contribute to the realisation of her aim or otherwise.

In general, however, if a person has a certain goal, it does not follow that actions that contribute to attaining or frustrating that goal are correct or incorrect respectively. Suppose, for example, that Damian's goal is to kill all children under five. Given this goal, it does not follow that, if Damian kills a four-year old, his doing 
so is correct. At most, it follows that, other things being equal, he takes it to be correct. So, returning to the case at hand, if (LIB) holds, at most it follows that, other things being equal, subjects take beliefs to be correct if and only they are true, not that beliefs are correct if and only they are true. To arrive at (CORRECT), one would require additional considerations which would show that the aim (LIB) attributes is an aim worth pursuing. ${ }^{24}$

For reasons explored above, I doubt such considerations are forthcoming, but perhaps it would be sufficient for the proponent of (LIB)'s explanatory purpose to explain the fact that subjects take (CORRECT) to be true, whether or not it is. ${ }^{25}$

If this explanation is to succeed, it requires an unrestricted version of (LIB). If one understood the relevant aim to be that which (NEOLIB) attributes, for example, one could not account for (CORRECT), for the simple reason that, unlike (NEOLIB), (CORRECT) is not limited to those propositions one considers. Many of the propositions one believes are not propositions one considers and yet it remains the case that, if any such proposition is true, believing it is correct.

Unfortunately, the unrestricted (LIB) does not fair much better as an explanation of subjects' commitment to (CORRECT). Granted, if (LIB) were true, this would explain the fact that subjects take truly believing to be correct (since doing so accords with their goal), but it would not explain the fact that subjects take falsely believing not to be correct, i.e. to be incorrect. (LIB)'s suggestion that subjects aim at truth is consistent with the idea that they also aim at falsehood; perhaps subjects aim to believe all propositions. Were a person to have this as her goal, she would take believing falsehoods to be correct. Indeed, were a person to have the more modest goal of believing exactly ten falsehoods, she would not take believing falsehoods in general to be incorrect. For this reason, (LIB) is explanatorily inadequate; at most, it explains one half of (CORRECT). 
One might object that it is not possible to aim to believe all or any falsehoods. However, while I am sympathetic to this thought, it is not one (LIB)'s proponent is entitled to, since nothing in her conception of belief's aim supports it.

Consider instead (CON). For reasons explored above, if (CON) is true, (CORRECT) does not follow, at least pending considerations that show that aiming only to believe the truth is an aim worth pursuing. I am confident that one could muster such considerations but, for present purposes, I shall focus on whether (CON) could explain the fact that subjects endorse (CORRECT), whether or not they are right to do so.

Unlike (LIB), (CON) straightforwardly accounts for the fact that subjects take believing falsehoods to be incorrect. Doing so conflicts with the aim of believing only the truth.

One might object that, just as (LIB) fails to explain the fact that subjects take false beliefs to be incorrect, so (CON) fails to explain the fact that subjects take true beliefs to be correct. According to (CON), subjects aim not to believe falsehoods, but this is consistent with the aim of not believing truths, i.e. of believing nothing. Were a person to have this as her goal, the objection continues, she would not take believing truths to be correct. For this reason, (CON) is explanatorily inadequate.

One can resolve this problem by assuming that $(\mathrm{CON})$ specifies the unique general aim of belief, or at least that believers do not also aim not to believe truths. This seems a legitimate assumption and it would be sufficient to guarantee that (CON) accounts for believers' commitment to (CORRECT). Suppose that, while (only) aiming not to believe falsehoods, a subject finds herself believing a truth. Believing this truth is not in the service of the subject's aim but nor is it in conflict with it, so her doing so is not incorrect; hence, it is correct. ${ }^{26}$ 
(LIB)'s proponent might ask why this move is not available to her, why she cannot equally assume either that (LIB) specifies the unique general aim of belief or at least that subjects do not also aim to believe falsehoods. However, this assumption is insufficient to guarantee that (LIB) accounts for believers' commitment to (CORRECT). Suppose that, while (only) aiming to believe truths, a subject finds herself believing a falsehood. Believing this falsehood is not in the service of the subject's aim, but it is not in conflict with it, so her doing so is not incorrect; hence, it is correct. In light of this, it seems that Platts is wrong to claim that the thought that 'beliefs aims at the truth' implies that 'falsity is a decisive failing in a belief' (1997, p. 256) ${ }^{27}$ It is (CON), not (LIB), which has this implication.

Surely, one might object, if a subject aims to believe the truth and believes a falsehood, she is failing in her aim. Hence, if she aims to believe the truth, believing a falsehood is incorrect, given that aim (cf. Littlejohn 2010, p. 80).

This is mistaken - to say that a subject aims to believe the truth is to say nothing whatsoever about her attitude toward falsity. Suppose that I aim to drink coffee. Suppose also that I drink whiskey. Am I thereby failing in my aim? No-I might drink whiskey and coffee, or even whiskey in coffee, and, moreover, I might aim to do so. Only if my aim were to drink only coffee would I be failing in that aim in drinking whiskey.

One might respond to this as follows. Drinking coffee does not preclude drinking whiskey. Hence, drinking whiskey does not thwart my aim to drink coffee. In contrast, believing a falsehood precludes believing a truth. Hence, believing falsely thwarts a subject's aim of believing truly. But this is mistaken. First, believing a falsehood does not preclude truly believing lots of other propositions. Second, believing falsely that $p$ does not even preclude believing truly that not- $p$ (at least, when the inconsistency is not apparent). Hence, if a subject aims to believe the truth, 
it does not follow from the fact that she believes a falsehood that she is failing in her aim. All of this is just a long way of saying that one must not confuse (CON) with (LIB).

Perhaps (LIB)'s proponent could muster considerations that show that having false beliefs ultimately thwarts the aim of believing the truth. However, such considerations are likely to be not only contentious but complex and sophisticated. Recall that (LIB) is supposed to explain subjects' unreflective, immediate acceptance of (CORRECT); thus, it would surely count against (LIB) if it presents such acceptance as mediated by appreciation of relatively arcane matters.

I have argued that (LIB) fails to account for subjects' commitment to (CORRECT). In contrast, (CON) straightforwardly explains why subjects—safely excluding those who aim to believe nothing - are committed to (CORRECT). A remaining worry with (CON) might be that, even if it can explain the fact that subjects take false belief to be incorrect, it cannot explain the fact that they take belief to be the only correct attitude to have toward a truth; not believing or withholding belief from a truth would be consistent with the aim specified by (CON) and so, by the lights of that aim, correct.

This is true but it does not point to a vice of (CON) but a virtue. It is no part of the above platitude that belief is the uniquely correct attitude to have towards a truth; (CORRECT) only claims that believing the truth is correct, not that it is the correct attitude to have. And that seems right. Unlike believing a falsehood, it is not a mistake not to believe a certain truth. Presumably, there is a truth about how many hairs are to be found on David Cameron's arms. I am surely not in error in not believing it.

No doubt there are situations in which it would be a mistake not to believe a truth. Suppose that I am a referee at a football match and, while distracted, fail to see that a goal has been scored, as a result of which I fail to believe this. In this case, my 
not believing the truth is incorrect, but this stems from other considerations than the truth of a given proposition alone — relating to my responsibilities as a referee-or from other aims than that which (CON) attributes - the aims of football. ${ }^{28}$

These remarks point to a further flaw in (LIB); it implies that belief $i s$ the uniquely correct attitude to have toward a truth — since believing the truth is the only thing that accords with the aim (LIB) attributes — and so it implies that it would be incorrect to do anything other than believe a truth, including not believing it. This implication, I have argued, is false.

So, it turns out that (LIB) not only fails to account for the fact that subjects take false beliefs to be incorrect but wrongly suggests that subjects take anything other than belief in a truth to be incorrect. In contrast, (CON) succeeds in accounting for subjects' commitment to no more and no less than (CORRECT).

\section{Demanding evidence}

In this section, I shall consider attempts to appeal to belief's aim to explain certain facts about evidence. I shall argue, first, that (LIB) and (CON) present very different accounts of the normative force or role of evidence and, second, that the picture (CON) presents is, despite appearances perhaps, more accurate than that which (LIB) presents. $^{29}$

For present purposes, I shall take evidence to be constituted by facts. For a fact to be one's evidence, for one to be in a position to believe on the basis of it, one has to believe that that fact obtains. ${ }^{30}$ If one is not sympathetic to this conception of evidence, it should be possible to replace it with one's preferred alternative without affecting the arguments. $^{31}$

Consider (LIB). Suppose that Holly's shoes are in the hall and that this is evidence that Holly is home. For reasons explored in the previous section, if (LIB) 
were true, it would not follow that this evidence is a normative reason for one to believe that Holly is home, i.e. a consideration that speaks in favour of believing this - that depends on whether the aim it attributes is worth pursuing. Again, for reasons explored earlier, I doubt it is but I shall not press that point here. For present purposes, it is enough to note that, if (LIB) were true, it would follow that we take evidence that Holly is home to be a pro tanto reason for believing that she is home. ${ }^{32}$ We would take this evidence to be a consideration that speaks in favour of so believing because the fact that Holly's shoes are in the hall indicates that believing that Holly is home accords with the aim of believing the truth, i.e. indicates that the belief that Holly is home is true. Moreover, if the reason provided by the evidence that Holly is home is undefeated, we would take it to follow that one ought to believe this, given the evidence. ${ }^{33}$ More generally, (LIB) suggests that subjects take evidence to be, or to provide, reasons to believe. ${ }^{34}$

Next, suppose that there are epistemic norms governing belief. Among them might be norms relating to evidence. (LIB) would seem to suggest that belief is governed by the following general principle, or at least that believers are committed to it:

(PRE) For any $p$, if a subject has (sufficient) evidence that $p$, then she should believe that $p .^{35}$

One way to construe this is instrumentally. The thought is that, if one aims to believe the truth, one is committed to taking the means to fulfilling that aim. ${ }^{36}$ As Owens neatly summarises the idea, though he does not endorse it, if the goal of belief is truth, 'epistemic norms are instructions about how to reach that goal' (2003, p. 283). ${ }^{37}$

Compare (CON). Suppose again that the fact that Holly's shoes are in the hall is evidence that she is home. Unlike (LIB), (CON) does not suggest that we take this evidence to be a normative reason for one to believe that Holly is home, i.e. a 
consideration that speaks in favour of believing this. Rather, if (CON) were true, it would follow that we take it to be the case that, given the evidence that Holly is home, there is no reason not to believe that she is home. On this picture, we take such evidence to be a warrant or entitlement — though not a reason — to believe that Holly is home because the fact that her shoes are in the hall indicates that this belief will not conflict with the aim to avoid falsehood, i.e. it indicates that the belief that Holly is home is true. Moreover, if the warrant or entitlement provided by the evidence that Holly is home is undefeated, we would take it to follow that one may believe this, given the evidence, though not that one ought to do so.

Suppose instead that Holly's shoes are not in the hall and that this is evidence that she is not home. (CON) suggests that we take this evidence to be a pro tanto reason not to believe that Holly is home. Subjects would take this evidence to be a consideration that speaks against believing that Holly is home because the fact that her shoes are not in the hall indicates that this belief will conflict with the aim to avoid falsehood, i.e. indicates that the belief that Holly is home is false. Moreover, if the reason not to believe that Holly is home provided by the evidence is undefeated, we would take it to follow that one should not believe this, given the evidence.

Finally, suppose again that there are epistemic norms governing belief, including norms relating to evidence. Unlike (LIB), (CON) does not suggest that belief is governed by (PRE), since (PRE) does not specify a means of fulfilling the aim (CON) attributes. ${ }^{38}$ However, (CON) does imply that belief is governed by the following general principles:

(PRO) For any $p$, if a subject has (sufficient) evidence that it is false that $p$, she may not believe that $p$.

(PER) For any $p$, if a subject has (sufficient) evidence that $p$, she may believe that $p$. 
The thought behind (PRO) is that, if one aims to believe only the truth, one is committed to taking the means to fulfilling that aim, while (PER) provides general guidance as to when believing is not in conflict with that aim.

To summarise, given (LIB), one would expect evidence that $p$ to be a reason to believe that $p$, and for belief in general to be subject to (PRE). In contrast, given (CON), one would expect evidence that $p$ to be a warrant to believe that $p$, evidence that not $p$ to be a reason not to believe that $p$, and for belief in general to be subject to both (PRO) and (PER).

It has not been recognised that (LIB) does not imply that subjects take evidence that a proposition is false to be a consideration that speaks against believing it. As discussed earlier, for all that (LIB) says, a subject might aim to believe all propositions, in which case evidence that a proposition is false would not be an indication that believing it would conflict with her aim. Likewise, (LIB) fails to explain (PRO) since, once again, it says nothing about subjects' attitudes toward falsity; believing propositions in the face of evidence is not in conflict with the aim (LIB) attributes. ${ }^{39}$

This reveals (LIB) to be explanatorily inadequate. It is a strike against (LIB) that it fails to explain the fact that we take evidence against a proposition to be a reason not to believe it and our commitment to the seemingly plausible (PRO). (If (LIB) fails in this respect, then evidently (NEOLIB) fails too.)

One might think that it is equally a strike against (CON) that it fails to explain the fact that we take evidence that a proposition is true to be a reason to believe it and our commitment to the seemingly plausible (PRE). Indeed, the idea that evidence that $p$ is, as such, reason to believe that $p$ is widespread. ${ }^{40}$ However, while full discussion of this view is beyond the scope of this paper, I shall make a case for thinking that it is false while accommodating the thoughts that might lie behind it. 
It is not clear that, in general, one has reason to believe, or ought to believe, that for which one has evidence. ${ }^{41}$ Any given fact is evidence for an infinite number of propositions. That Holly's shoes are in the hall might be evidence for the belief that Holly is home, but it is equally evidence for the belief that footwear is in the hall, that the house has a hall, that shoes exist, that Holly has legs, that Holly is not a kangaroo, that there is no golden trumpet in the space currently occupied by Holly's shoes, that either Holly is home or the moon is made of cheese, and so on. In light of this, it should be clear that it cannot be the case that one has reason to believe everything for which one has evidence or that one ought to. There are infinitely more such propositions than one can believe, and as many such propositions that are too complex for one to believe, and it cannot be the case that one ought or has reason to do something one cannot do. The principle that ought implies can is, of course, controversial, and even those who endorse the principle disagree over how it applies, but the case need not rest on it. The crucial point is that it is implausible to hold that subjects have reason to believe or should believe all and any propositions for which there is evidence when the vast majority of those propositions are utterly trivial and not worth believing.

The thought above echoes those expressed in $\$ 3$ and I shall not repeat the arguments here. But it is worth adding that our practices of epistemic assessment and criticism seem to accord with the picture which (CON) presents. For example, suppose that Elliot knows that Holly's shoes are in the hall and, on the basis of this and perhaps other considerations, comes to believe that she is home but not that there is no golden trumpet in the space currently occupied by Holly's shoes. Surely, we would not take Elliot for this reason alone to be epistemically irresponsible or out of order and are not in the habit of criticising people for not having such beliefs. ${ }^{42}$ This is just as well, since we are constantly guilty of not believing an endless number of such 
things! Perhaps these considerations are not decisive but they suggest that the more austere picture of evidence and the norms governing it which (CON) presents is more accurate than the excessively demanding picture (LIB) presents.

Surely, one might object, there are cases in which we criticise subjects for not believing propositions for which they possess sufficient evidence or in which we take the evidence to be a reason for having certain beliefs. Indeed, arguably such cases are common.

This is true. But (CON) is entirely consistent with this. Such cases are ones in which, given the circumstances, we take a subject to have reasons to believe certain things, or to be subject to certain norms. For example, suppose that Stanley is a detective investigating a murder and there is overwhelming evidence that Plum killed Peacock in the conservatory with the candlestick. We would typically take Stanley to have reason to believe this and, if he fails to do so, we would judge that he does not believe as he should. However, that Stanley has such reasons and is open to such assessment is surely not due merely to the evidence he has but, in addition, the need to restore justice, the responsibility he assumes in taking on the role of detective, his aims in investigating the murder, and so on. So, while (CON) does not account directly for cases in which, given the evidence, a subject has reason or ought to believe certain things, it certainly allows for them.

To put the thought another way, it is useful to distinguish a reason to form a belief as to whether $p$ and a reason for believing that $p$. In my view, contra (LIB), we do not take the mere fact that one has evidence that $p$ to be a reason for believing that $p$. However, if there is reason to form a belief as to whether $p$, then the fact that one has evidence that $p$ is a reason to believe that $p$. In the case above, we take Stanley's evidence to be a reason for him to believe that Plum killed Peacock, given also that we take him to have reason to form a belief about this matter. 
The proponent of (LIB) might reply that her view was only ever that subjects aim to belief a truth if they have reason to have a belief about that matter. If so, then (LIB) is, to say the least, a misleading formulation of that view. Moreover, and more importantly, (LIB) is superfluous; we only need (CON) to explain what is going on in such cases. If for some reason one has to form a belief as to whether $p$, and if one aims not to believe falsely, then one has to believe truly, in which case, one would take evidence that $p$ to be reason to believe that $p$.

Note also that (LIB), understood in the above way, is explanatorily inadequate. To return to an earlier issue, that subjects aim to believe a truth if they have reason to have a belief about that matter would not account for their commitment to (CORRECT), for the straightforward reason that (CORRECT) is not restricted to those propositions one has reason to adopt a doxastic attitude toward. So, the unrestricted (CON) is still called for.

Returning to the issue at hand, I acknowledged that (CON) does not suggest that subjects take evidence that $p$ to be a reason to believe that $p$, or that subjects endorse (PRE). However, I have argued that, rather than being a shortcoming, this might count in (CON)'s favour. While a full exploration of the issue is beyond the scope of this paper, it is at least not obvious that we think that subjects have reason to believe or should believe a proposition simply because there is evidence for it. Moreover, (CON)'s proponent can account for the fact that there are many cases in which, given other factors, we do think a subject should or has reason to believe a proposition given the evidence, which in turn might satisfy the kinds of intuitions which might lead one to advance a principle like (PRE).

In summary, I have stressed that (CON) and (LIB) present very pictures of the normative status of evidence and the general principles concerning it, and have argued that the picture (CON) is the more accurate. 


\section{$6 \quad$ Particular and general}

According to (LIB), as I have presented it, subjects aim to believe a proposition if it is true. While Velleman speaks readily of belief's aiming at the truth, his considered remarks attribute a more cautious aim to belief. According to Velleman, subjects have no 'global epistemological project of accumulating true beliefs'; they do not have 'designs on truths in general, or Truth in the abstract' (2000, p. 252). For Velleman, there is no general aim of belief as such; rather, there are particular aims one has in believing particular propositions. Specifically, in believing a certain proposition, one has the aim 'of getting the truth-value of that particular proposition right' (2000, pp. 251-252). As Velleman encapsulates the idea, 'each instance of belief must aim at the truth in its own right' $(2000$, p. 279$){ }^{43}$

Velleman's conception of (each) belief's aim is consistent with (CON). If, in general, I aim to believe only the truth, it would follow that, in believing any given proposition, I aim to believe it only if it is true. However, Velleman presents his account of the particular aims one has in believing particular propositions as opposed to the idea that there is some general aim of belief. Unfortunately, in avoiding generality, Velleman relinquishes explanatory power. For Velleman, the relevant aim does not, as it were, kick in until the belief is formed. As a result, he cannot appeal to belief's aim in trying to account, for example, for the fact that we take evidence against the truth of a proposition to be a reason not to believe it. ${ }^{44}$

To appreciate this, suppose that I believe that Holly is home. According to Velleman, in believing this, I aim not to believe falsely. It follows that, if there is evidence that Holly is not home, I have some reason not to believe that she is home, i.e. to give up my belief, since I have some reason to think that continuing to believe that Holly is home would conflict with my aim in doing so. So far so good. However, 
suppose that I have no belief at all as to whether Holly is home and there is evidence that she is not home. Intuitively, this evidence remains a reason not to believe that Holly is home. How could Velleman account for this, given that he denies that subjects have a general goal of not believing falsehoods and holds that subjects only have goals with respect to the beliefs they actually possess? One cannot explain the reasons there are for not having a belief by appeal to an aim one does not have (since one does lacks the corresponding belief).

Velleman might try to account for the reasons there are for not having the relevant belief by appeal to the aim one would have if one were to form that belief. But that will not work. At most, that one would have an aim if one were to have a certain belief would explain the reasons one would then have, i.e. the reasons one has in the counterfactual world, not the reasons one has in the actual world. Suppose I aim to bake a cake. Given this, that my cupboards are bare might be a reason to shop for ingredients. But suppose I do not aim to bake a cake. In that case, that my cupboards are bare is no longer a reason to shop for ingredients. Moreover, from the fact that I would have a reason to shop for ingredients if I were to aim to bake a cake, it hardly follows that the fact that my cupboards are bare is a reason to shop for ingredients.

So, given that Velleman attributes to subjects only particular aims in believing particular propositions, and not a general aim not to believe certain things, he is unable to explain certain facts about reasons for beliefs which subjects do not presently have. This is not, of course, to show that Velleman is wrong to suggest that subjects, in believing a particular proposition, aim only to believe the truth, but to suggest that such particular aims cannot do the explanatory work he asks of them.

\section{$7 \quad$ Conclusion}


According to (LIB), a subject aims to believe a proposition if it is true. According to (CON), a subject aims to believe a proposition only if it is true, which is to say, a subject aims not to believe a proposition if it is false. I have argued that $(\mathrm{CON})$ is more plausible as a characterisation of belief's aim than (LIB), that (CON) has greater explanatory power than (LIB), since it alone accounts for the correctness condition for belief, that (CON) presents a more satisfactory account of the normative force of evidence than (LIB), and that Velleman's 'particularist' alternative is even more lacking in explanatory power. If right, this suggests that, though subjects do not aim to believe the truth, if they did, they should believe (CON). ${ }^{45}$

Philosophy, Faculty of Humanities,

University of Southampton

\section{References}

Alston, W. (1989). Epistemic Justification. Ithaca, New York: Cornell University Press.

Alvarez, M. (2010). Kinds of Reasons. Oxford: Oxford University Press.

Boghossian, P. (2008). Content and Justification. Oxford: Oxford University Press.

Bonjour, L. (1985). The Structure of Empirical Knowledge. Cambridge, Massachusetts: Harvard University Press.

David, M. (2001). 'Truth as the Epistemic Goal', in M. Steup (ed.), Knowledge, Truth, and Duty. Oxford: Oxford University Press.

David, M. (2005). 'Truth as the Primary Epistemic Goal: A Working Hypothesis', in M. Steup and E. Sosa (eds.), Contemporary Debates in Epistemology. Oxford: Blackwell.

Engel, P. (2002). Truth. Chesham: Acumen. 
Engel, P. (2004). 'Truth and the Aim of Belief', in D. Gillies (ed.), Laws and Models in Science. London: King's College Publications.

Feldman, R. (2000). ‘The Ethics of Belief', Philosophy and Phenomenological Research 60, pp. 667-695.

Feldman, R. and Conee, E. (1985). 'Evidentialism', Philosophical Studies 48, pp. 1534.

Foley, R. (2001). 'The Foundational Role of Epistemology in General Theory of Rationality', in A. Fairweather and L. Zagzebski (eds.), Virtue Epistemology. Oxford: Oxford University Press.

Grimm, S. (2008). 'Epistemic Goals and Epistemic Values', Philosophy and Phenomenological Research 77, pp. 725-744.

Heal, J. (1987/8). 'The Disinterested Search for Truth', Proceedings of the Aristotelian Society 88, pp. 97-108.

Humberstone, L. (1992). 'Directions of Fit', Mind 101, pp. 59-83.

Hyman, J. (2006). 'Knowledge and Evidence', Mind 115, pp. 891-915.

Kelly, T. (2003). 'Epistemic Rationality as Instrumental Rationality: A Critique', Philosophy and Phenomenological Research 66, pp. 612-640.

Kelly, T. (2007). 'Evidence and Normativity', Philosophy and Phenomenological Research 75, pp. 465-474.

Kvanvig, J. (2003). The Value of Knowledge and the Pursuit of Understanding. Cambridge: Cambridge University Press.

Kvanvig, J. (2005). 'Truth and the Epistemic Goal', in M. Steup and E. Sosa (eds.), Contemporary Debates in Epistemology. Oxford: Blackwell.

Littlejohn, C. (2010). ‘Moore's Paradox and Epistemic Norms', Australasian Journal of Philosophy 88, pp. 79-100. 
Lynch, M. (2004). 'Minimalism and the Value of Truth', Philosophical Quarterly 54, pp. 497-517.

Lynch, M. (2005). True to Life. Cambridge, Massachusetts: MIT Press.

Lynch, M. (2009). 'The Values of Truth and the Truth of Values', in A. Haddock, A. Millar and D. Pritchard (eds.), Epistemic Value. Oxford: Oxford University Press.

Malebranche, N. (1997). The Search After Truth, T. Lennon and P. Olscamp (eds. trans.). Cambridge: Cambridge University Press.

McHugh, C. (2011). 'What Do We Aim at When We Believe?', dialectica 65, pp. 369-392.

McHugh, C. (Forthcoming). 'Belief and Aims', Philosophical Studies.

Millar, A. (2004). Understanding People. Oxford: Oxford University Press.

Millar, A. (2009). 'How Reasons for Action Differ from Reasons for Belief', in S. Robertson (ed.), Spheres of Reason. Oxford: Oxford University Press.

Nelson, M. (2010). 'We Have No Positive Epistemic Duties', Mind 119, pp. 83-102.

Owens, D. (2003). 'Does Belief Have an Aim?', Philosophical Studies 115, pp. 283305.

Papineau, D. (1999.) 'Normativity and Judgement', Aristotelian Society Supplementary Volume 73, pp. 16-43.

Platts, M. (1997). Ways of Meaning, $2^{\text {nd }}$ ed. Harvard Massachusetts: MIT Press.

Railton, P. (1994). 'Truth, Reason, and the Regulation of Belief', Philosophical Issues 5, pp. 71-93.

Reisner, A. (2008). 'Weighing Pragmatic and Evidential Reasons for Belief', Philosophical Studies 138, pp. 17-27.

Shah, N. (2003). 'How Truth Governs Belief', Philosophical Review 112, pp. 447-482. 
Shah, N. and Velleman, J. D. (2005). 'Doxastic Deliberation', Philosophical Review 114, pp. 497-534.

Sosa, E. (2001). 'For the Love of Truth?', in A. Fairweather and L. Zagzebksi (eds.), Virtue Epistemology. Oxford: Oxford University Press.

Sosa, E. (2003). 'The Place of Truth in Epistemology', in M. DePaul and L. Zagzebski (eds.), Intellectual Virtue. Oxford: Oxford University Press.

Steglich-Petersen, A. (2006). 'No Norm Needed: On the Aim of Belief', Philosophical Quarterly 56, pp. 499-516.

Steglich-Petersen, A. (2009). 'Weighing the Aim of Belief', Philosophical Studies 145, pp. 395-405.

Steglich-Petersen, A. (2011). 'How to be a Teleologist about Epistemic Reasons', in A. Reisner and A. Steglich-Petersen (eds.), Reasons for Belief. Cambridge: Cambridge University Press.

Velleman, J. D. (2000). The Possibility of Practical Reasoning. Oxford: Oxford University Press.

Wedgwood, R. (2002). 'The Aim of Belief', Philosophical Perspectives 16, pp. 267297.

Whiting, D. (2010). 'Should I Believe the Truth?', dialectica 64, pp. 213-224.

Whiting, D. (Forthcoming). 'Nothing but the Truth: On the Norms and Aims of Belief', in T. Chan (ed.), The Aim of Belief.

Whiting, D. (Manuscript). 'The True and the Good (or the Bad and the False)'.

Wiggins, D. (1998). Needs, Values, Truth, $3^{\text {rd }}$ ed. Oxford: Oxford University Press. Williams, B. (1973). Problems of the Self. Cambridge: Cambridge University Press. Williamson, T. (2000). Knowledge and its Limits. Oxford: Oxford University Press. Zagzebski, L. (2003). 'Intellectual Motivation and the Good of Truth', in M. DePaul and L. Zagzebski (eds.), Intellectual Virtue: Oxford University Press. 


\section{Notes}

${ }^{1}$ Both quotes are from Malebranche 1997, p. 1.

${ }^{2}$ For endorsements of (LIB) or some version of it, see Boghossian 2008, p. 101; Engel 2002, p. 57; Humberstone 1992; Littlejohn 2010; Lynch 2004, p. 499; Millar 2004, p. 43; Millar 2009, p. 140; Platts 1997, p. 256; Railton 1994; Shah 2003, p. 459; Shah and Velleman 2005, pp. 498-499; Steglich-Petersen 2006; Steglich-Petersen 2009; Wedgwood 2002, p. 267; Wiggins 1998, p. 148; Williams 1973, p. 136; Zagzebski 2003, pp. 135-136. A related idea is that true belief is the cognitive or epistemic goal (see, for example, Bonjour 1985, p. 7).

An important caveat: those cited might not all understand (LIB) in the same way or as I do. I shall outline how I interpret (LIB) in §2 and consider alternative interpretations at various stages.

${ }^{3}$ I endorse (CON) in Whiting 2010, p. 217. Cf. n4 below.

${ }^{4}$ Millar, for example, readily switches from the phrase 'belief aims at truth' to the phrase 'belief aims only at truth' (2004, pp. 43-44; cf. Shah and Velleman 2005, p. 498; Wedgwood 2002).

Velleman repeatedly claims that belief aims at the truth (e.g. 2000, pp. 16-7, $231,244)$, though on occasion he formulates the aim as that of believing only what is true (e.g. 2000, pp. 25, 113). As I shall discuss below (§6), his considered remarks suggest a rather different understanding of belief's aim to that which either (LIB) or (CON) capture, at least I construe them, an understanding which seems to be shared by, among others no doubt, Humberstone (1992), McHugh (Forthcoming) and SteglichPetersen (2009). 
${ }^{5}$ Debates concerning the idea that belief aims (only) at truth overlap with debates concerning the value or goodness of true belief. I shall not explicitly engage with the latter here, though much of what follows bears on it. For discussion, see Whiting Manuscript.

${ }^{6}$ Thanks to an anonymous referee for this journal for prompting this clarification.

${ }^{7}$ The most prominent proponent of this view is Williamson (2000). For recent defences of the claim that belief aims at knowledge, see Engel 2004; McHugh 2011. For criticism, see Littlejohn 2010; Whiting Forthcoming.

${ }^{8}$ Alston, for example, claims that 'the epistemic point of view [...] is defined by the aim of maximizing truth and minimizing falsity in a large body of beliefs' (1989, pp. 83-84), while David characterises the goal as one of 'believing truths and not believing falsehoods' (2001, p. 152; cf. Foley 2001; Kvanvig 2005). Note that these philosophers seem to be primarily concerned with the aim of inquiry, not of belief, or at least they do not really distinguish the two.

${ }^{9}$ For hints, see $\mathrm{n} 25$ and $\mathrm{n} 32$ below.

${ }^{10}$ Like Millar (2004, pp. 56ff), one might hold that belief is regulated for truth nonintentionally by sub-personal mechanisms and in some cases intentionally by the subject.

${ }^{11}$ This paragraph draws heavily on Alvarez 2010, ch. 4.

${ }^{12}$ Note that, if believing (only) the truth is one's intention, it does not follow that all of one's beliefs are formed intentionally, any more than it would follow from the fact that my intention is to lose weight that all the weight loss I experience is intentional. ${ }^{13}$ Certainly the remarks of many of those cited above (n2) and the uses they put (LIB) to suggest as much. Some of those who commit themselves in print to (LIB) might, on reflection, endorse $(\mathrm{CON})$ once the contents of the aims each thesis attributes are made 
explicit. In that case, the remarks that follow aim to show that they would be right to do so.

${ }^{14}$ Since I am not sympathetic to the idea that there might be propositions which are neither true nor false, I shall assume that, if a proposition is not true, it is false.

However, nothing in what follows hangs on this assumption. To allow for truth-value gaps, one need only replace talk of, say, the aim not to believe a proposition if it is false with talk of the aim not to believe a proposition if it is not true.

${ }^{15}$ Of course, we speak loosely: I might say that I aim to have only sons, when context makes it clear that my aim is to have children, though only male children.

${ }^{16}$ Velleman (2000, p. 251) raises this issue when motivating his conception of belief's aim (see §6). In debates whose main focus is not, or not only, the idea that belief has an aim, in the sense explored here, it is very common to appeal to propositions concerning trivial matters so as to undermine the idea that true belief as such is something which subjects value or have as their goal (see, among many others, David 2005, pp. 298-299; Feldman 2000, p. 683; Heal 1987/88; Kelly 2003, pp. 624-625; Sosa 2001).

${ }^{17}$ Lynch (2009, p. 227) says something along these lines, though his explicit focus is the aim of inquiry, not of belief.

${ }^{18}$ I discuss these issues in much more depth, in the context of a debate over the value of truth, in Whiting Manuscript.

${ }^{19}$ Wedgwood (2002) suggests a restriction of this sort (though for his conception of talk of the aim of belief, see $\mathrm{n} 23$ below).

Another way to make (LIB) more plausible would be to restrict it to those propositions one is curious about or interested in. For a critical investigation of this suggestion, see Grimm 2008. Though the focus of Grimm's discussion appears to be 
the aim of inquiry, not of belief, it makes it clear that to restrict (LIB) in this way would prevent it from being put to some of the explanatory uses discussed below.

Alternatively, rather than restrict the aim to those propositions one considers, one might restrict it to those propositions with respect to which one actually has, or is going to have, beliefs. I shall explore such a proposal in detail in $§ 6$.

${ }^{20}$ I have encountered this objection several times in discussion.

${ }^{21}$ Contra Kelly 2003, p. 627.

${ }^{22}$ There are notorious problems facing the idea that belief is subject to normative considerations, stemming from the fact that one cannot believe at will (see Alston 1989, ch. 5). Since this issue is tangential to the concerns of this paper, I shall not discuss it.

${ }^{23}$ Boghossian (2008), Engel (2004), Lynch (2009) and Wedgwood (2002) present (CORRECT) and related norms as reformulations of (LIB), rather than as explained by it in any robust sense. Still, the reasons given below for doubting that (LIB) explains (CORRECT) equally count against the thought that the former is an interpretation of the latter.

${ }^{24}$ I am not convinced by attempts to get around this problem which appeal to the thought that the relevant aim is constitutive of believing (Velleman 2000, p. 16). It might be true that having a certain aim is constitutive of $\varphi$ ing and equally true that that aim is not worth pursuing (in which case, it is not worth $\varphi$ ing).

${ }^{25}$ It is hard to see how one could explain the fact that, at the personal level, subjects take true and false beliefs to be correct and incorrect respectively by appeal to belief's aim if one understands that aim as a matter of belief states being causally regulated for truth and falsity at the sub-personal level. 
${ }^{26}$ This presupposes something I have argued for elsewhere (Whiting 2010), namely, that to say that $\varphi$ ing is correct is only to say that $\varphi$ ing is acceptable or okay, not that $\varphi$ ing is called for or required.

${ }^{27}$ One finds this suggestion in many discussions of belief's aim (see, for example, Boghossian 2008, p. 101; Wiggins 1998, p. 148; and Williams 1973, p. 137). By the same token, Engel is wrong to claim that, if 'belief in general aims at truth', 'one ought to believe that $p$ only if $p$ is true' (2002, pp. 128-9; cf. Littlejohn 2010, pp. 8081).

${ }^{28}$ This example is not meant to suggest that only practical considerations make not believing a truth a mistake. Suppose, for example, that I have just seen a proof of a certain mathematical theorem. If one thinks that it would be wrong not to believe the theorem (I am not sure about this), one might account for this by appeal to a requirement of rationality, such as that one should (believe that $q$, if one believes that $p$ and believes that $p$ entails $q$ ). Whether there are such requirements and how to understand them is controversial. The important point for present purposes is that a proponent of $(\mathrm{CON})$ can accept that there are circumstances in which, irrespective of practical considerations, we would take it to be incorrect not to believe a truth. ${ }^{29}$ The idea that belief aims (only) at truth bears on the debate-dating back at least to the exchange between Clifford and James_concerning whether non-evidential considerations can justify or provide reason for belief. Appealing to the specification of belief's aim which I favour, namely, (CON), one might suggest that a subject cannot take practical considerations to provide reason or justification for believing that $p$, since those considerations do not indicate that, were she to believe that $p$, she would accord with her aim to believe a proposition only if it is true. While I think there is 
something to this line of thought, it is beyond the scope of this paper to explore the issue further.

${ }^{30}$ Some make the stronger claim that, if the fact that $p$ is to be one's evidence, one must know that $p$ (Hyman 2006; Williamson 2000). I need not take a stand on this issue here.

${ }^{31}$ For example, some hold that the notion of evidence is a normative notion and, specifically, that evidence that $p$ is reason to believe that $p$ (see Kelly 2007). Operating with this view, one could recast the issue of whether subjects take evidence that $p$ to be a reason to believe that $p$ as that of whether subjects take some fact indicating that $p$ to be evidence that $p$ (and so a reason to believe that $p$ ).

${ }^{32}$ It is hard to see how one could explain the fact that, at the personal level, subjects take evidence to be a reason for or against believing by appeal to belief's aim if one understands that aim as a matter of belief's being causally regulated for truth and falsity at the sub-personal level.

${ }^{33}$ Steglich-Petersen (2011) appeals to the idea that belief aims at truth in advancing a view according to which claims about what one ought to believe do not follow immediately from claims about what one has (most) reason to believe. Critically assessing his proposal is a task for another occasion.

${ }^{34}$ For an account of reasons for belief of this sort, see Millar 2004, pp. 42ff; Millar 2009; Velleman 2000, pp. 15-20, 182ff. This is a version of or related to the 'teleological' conception of justification, which is close to orthodoxy in epistemology, according to which justification is a 'means' to the goal of true beliefs (cf. Alston 1989, pp. 83-84; Bonjour 1985, pp. 7-8; David 2001; David 2005; Lynch 2009).

Note that, given (NEOLIB), indications of the truth of a proposition would only be a reason to believe that proposition if one considers it, which seems wrong. David 
(2001, p. 159) makes a similar point when discussing teleological conceptions of justification of the sort sketched above.

${ }^{35}$ What counts as sufficient evidence is a thorny issue and, since doing so would distract us from more immediate concerns, I shall not tackle it here.

${ }^{36}$ For ('teleological') proposals concerning epistemic norms along these lines, see Engel 2004, p. 82; Papineau 1999; Railton 1994, p. 75; Steglich-Petersen 2009, pp. 395-396; Wedgwood 2002, §4. For similar proposals, not explicitly framed in terms of belief's aim, see David 2001; David 2005; Foley 2001; Lynch 2005, pp. 13-15. ${ }^{37}$ Owens (2003) denies that one can explain epistemic or rational norms by appeal to an aim of belief. This is not the place to engage with his arguments. For critical discussion, see McHugh Forthcoming; Steglich-Petersen 2009.

${ }^{38}$ Contra Boghossian 2008, p. 101.

${ }^{39}$ Contra Littlejohn 2010, pp. 80-81; Millar 2009, p. 149.

${ }^{40} \mathrm{Cf}$. 'Indicators of truth count as reasons for belief' (Velleman 2000, p. 17). See also Kelly 2007. For similar suggestions by philosophers not participating in the debate over belief's aim, see Hyman 2006; Reisner 2008.

${ }^{41}$ The remarks in this paragraph accord with the view Nelson advances (2010), though his concern is not the idea that belief has an aim. Feldman briefly advances a similar line of thought (2000, pp. 678-679), in contrast to his earlier view (cp. Feldman and Conee 1985).

${ }^{42}$ Matters might be different if Elliot were to believe, not only that Holly’s shoes are in the hall, but also that this is (sufficient) evidence that she is home. In that case, one might take Elliot to be violating a requirement of rationality (cf. n28 above).

Matters might also be different if one were to ask Elliot if there is no golden trumpet... First, this might lead Elliot to form a belief on this matter, or provide him 
with some reason to do so. I shall consider such cases shortly. Second, it might prompt Elliot to consider what his evidence is evidence for, which might reintroduce requirements of rationality.

${ }^{43}$ Humberstone (1992) presents a similar 'particularized' conception of belief's aim, by appeal to which he suggests one might account for both belief's correctnesscondition and the evidential norms governing the attitude. Perhaps this captures the considered conception of belief's aim that others who explicitly endorse (LIB) have (cf. McHugh Forthcoming).

Like Velleman, Sosa (2003) avoids attributing to subjects a general desire for (only) true beliefs. Instead, he suggests that, for any belief we have, we want it to be true rather than false, though he doubts this claim can do much explanatory work. ${ }^{44}$ Contra Velleman 2000, pp. 182ff.

${ }^{45}$ I am grateful to Conor McHugh, Fiona Woollard, Jonathan Way, an anonymous referee and an audience at Southampton for extremely helpful comments on earlier versions of this material. I am also grateful to Philosophy and the Faculty of Humanities at the University of Southampton for supporting a period of research leave during which I was able to work on this paper. 